\section{Clinical Assessment of Rosemary- based Toothpaste (Rosmarinus officinalis Linn.): A Randomized Controlled Double-blind Study}

'Graduate Program in Dentistry, UFPE - Universidade Federal de Pernambuco, Recife, PE, Brazil

Correspondence: Alessandra Albuquerque Tavares Carvalho, Rua Prof. Moraes Rego, 1235, 50670-901 Recife, PE, Brasil. Tel +55-81-2126-8818. e-mail: alessandra.atcarvalho@gmail.com

Marcela A. A. Valones ${ }^{1} @$, Ingrid Carla Guedes Silva ${ }^{1}{ }^{\circ}$, Luiz Alcino Monteiro Gueiros ${ }^{1}{ }^{\circ}$, Jair Carneiro Leão ${ }^{1}{ }^{\circledR}$, Arnaldo F. Caldas $\mathrm{Jr}^{1}{ }^{\oplus}$, Alessandra Albuquerque Tavares Carvalho' ${ }^{10}$
The present study was to investigate the action of a toothpaste made from the extract of Rosmarinus officinalis Linn. (rosemary) in a clinical randomized, controlled, open and double-blind trial. One hundred and ten volunteers fulfilled the inclusion criteria and were randomly separated into two groups according to the toothpastes used: Group A (experimental) and Group B (control). They were assessed at baseline and 30 days after the study using the gingival bleeding index (GBI) and the plaque index (PI). Data analysis was conducted to calculate the effects of the two toothpastes on gingival bleeding and plaque, using measurements such as the excess relative risk (ERR), the Relative Risk Reduction (RRR), the Absolute Risk Reduction (ARR) and the Number Needed for Treatment (NNT). The two toothpastes provided similar results in terms of the reduction in the risk of gingival bleeding (relative and absolute): a reduction of 38\% in Group A, ERR $=0.38$; a reduction of 29.3\% in Group $B, E R R=0.293$; $A$ and $B$ reduced by $18 \% A R R=0.18)$. The reductions in bacterial plaque were also similar $(22.7 \%$ reduction in Group $A, R R R=0.227 ; 28 \%$ reduction in Group $B, R R R=0.28$ ). The number needed for treatment values for bleeding and plaque were $A$ and $B N N T=5$ and $A$ and $B N N T=7$, respectively. The rosemary-based toothpaste effectively treated gingival bleeding and reduced bacterial plaque, when compared with conventional toothpaste.
Key Words: Rosmarinus officinalis, phytotherapy, gingivitis, biofilm, toothpaste.

\section{Introduction}

The accumulation of dental biofilm is still a concern for dentists, given that it has been correlated with the etiology of diseases such as caries, periodontal disease and halitosis. The importance of controlling this biofilm has been greatly explored in the literature $(1,2)$. As well as the mechanical removal of bacterial plaque through brushing, a concentration of $0.2 \%$ chlorhexidine has become the standard substance used to control plaque worldwide. However, since this is a chemical product, it exhibits a series of adverse effects, such as an altered palate, as well as stains on the teeth, tongue and restorations, among others $(3,4)$.

The toothpastes that are used nowadays have both cosmetic and therapeutic purposes: they help clean the surface of teeth, freshen breath and combat the progression of caries and the accumulation of bacterial plaque, with an anti-inflammatory effect $(3,5)$. Several plantbased toothpastes are available on the market, and this trend has been increasing due to the fact that more and more people choose to use natural medicines rather than synthetic products (4). Herbal products are natural, inexpensive and have less undesirable effects. Their benefits have been universally accepted (6). Several plant species, including rosemary, have the power to inhibit the formation of dental biofilm by reducing the adherence of pathogens to dental surfaces, thereby avoiding the pathologies caused by its formation (2,6,7-9).

Rosmarinus officinalis Linn., known in Brazil as "alecrim" (rosemary), is a small aromatic bush, which is native to the Mediterranean region and belongs to the Lamiaceae family. This medicinal plant has anti-microbial, antifungal and antioxidant therapeutic properties, among many others, and is often used as a flavoring herb in the food industry. Its leaves are a great source of its properties, and are composed of terpenoids, flavonoids, phenols and essential oils. Each component has its own pharmacological properties, which make it an excellent raw material for products with multiple therapeutic functions (7,10-13).

The ever-increasing amount of natural substances incorporated into dental products, as well as the scarcity of studies in the literature addressing the safety and efficiency of these products, suggest the need for more studies of this type. In addition to this scarcity of data, scientific evidence related to the therapeutic properties of rosemary $(10-12,14)$ recommends the creation of rosemary-based toothpaste for clinical assessments. 
Therefore, the aim of this randomized, controlled, open, double-blind, clinical trial was to investigate the action of a new cosmeceutical (cosmetic with a therapeutic action) toothpaste containing extract of Rosmarinus officinalis Linn. (rosemary) on bacterial plaque and gingival bleeding, when compared with a conventional, fluoridated toothpaste that is commercially available.

\section{Material and Methods}

This randomized, controlled, open, double-blind, clinical trial was approved by the Human Research Ethics Committee of the Universidade Federal de Pernambuco (UFPE) under protocol number CAAE 02576212.1.0000.5208, in accordance with CONSORT criteria (REBEC: RBR-9F3CTB). The research was conducted in the Stomatology Clinic of the Department of Clinical and Preventive Odontology in the UFPE. All of the participants signed a free and informed consent form, in accordance with resolution 466/12 of the National Health Council, once the aims of the research had been explained to them.

\section{Study Subjects}

The volunteers were patients in the above-mentioned clinic, and were selected as they arrived for appointments. Based on the pilot-study, the sample was determined using PCSIZE software, (version 1.01(c), 1990 - Gerard E. Dallal, Andover, MA, USA), considering a type 1 error of 5\% and a confidence interval $(\mathrm{Cl})$ of $95 \%$. In total, 250 volunteers were assessed for eligibility: 140 were excluded for not fulfilling the inclusion criteria, for refusing to participate, or for other reasons. Thus, 110 subjects fulfilled the inclusion criteria, which were: males and females; aged between 18 and 45 years; with at least 20 healthy teeth in the oral cavity; without gingivitis, periodontitis or caries (based on a visual examination and probing with a millimetric periodontal probe). The following exclusion criteria were applied: smokers; pregnant women; diabetics; individuals using antibiotic, anti-inflammatory or antifungal medication at the time and individuals with orthodontic braces (Fig. 1)

\section{Preparation of Rosemary-Based Toothpaste}

The botanic material Rosmarinus officinalis Linn. was acquired in a local public market and identified through comparisons with material previously deposited in the Bento Pickel herbarium of the Instituto de Pesquisas Agrícolas de Pernambuco (IPA). The ethanolic extract of rosemary was produced in large quantities in the Laboratório de Coleção de Culturas, in the Antibiotics Department of the UFPE. This extract was then sent to SENSORIALE ${ }^{\circledR}$ Pharmaceuticals and Cosmetics (Recife-PE) for incorporation into a toothpaste formula. During this process, organoleptic characteristics such as color, flavor and odor were tested, while viscosity, abrasiveness, shine, $\mathrm{pH}$ and foam quality were also analyzed. The composition of the toothpaste respected the lethal dose (DL50) of rosemary (15) as a safety parameter. The final toothpaste produced contained a concentration of $5 \%$ of the extract (without fluoride).

\section{Study Protocol}

Upon entering the experiment, the volunteers were randomly divided into groups $A$ and $B$ using opaque envelopes, which were sealed and numbered in accordance with the random sequence in which the subjects were admitted to the study. The sealed envelopes contained the letter corresponding to the respective group. Since this was a double-blind study, neither the researcher nor the volunteers were aware of the toothpaste they had drawn. To hide the identity of the toothpastes, the products were labelled by the pharmacy in question, who were the only parties that knew the identity of the toothpastes. After the end of the clinical trial, the identity of the toothpastes was revealed: Group A used the experimental toothpaste and Group B used the conventional fluoridated toothpaste, which is commercially available in Brazil (Sorriso Dentes Brancos $^{\circledR}$, Colgate-Palmolive, Osasco, SP, Brazil). The selection of toothpaste $B$ was made due to the presence of fluoride and the relatively low quantity of additives in its formula. Thus, 55 patients were allocated to Group A (experimental rosemary-based toothpaste) and 55 patients were allocated to Group B (control-fluoridated toothpaste).

After the selections and randomization were completed, the patients began the experiment, which involved two stages, as follows: Stage 1 - Baseline: a clinical examination was conducted and the gingival bleeding index (GBI) and plaque index (PI) were recorded (16).

The GBI is obtained by examining all of the surfaces of the teeth (vestibular, lingual, mesial and distal). The presence or absence of gingival bleeding is determined by a delicate inspection of the gingival sulcus, using a periodontal probe recommended by the World Health Organization (WHO). The presence of gingival bleeding indicated a positive count, expressed as a percentage of the total number of gingival margins examined.

The PI involves an examination of the vestibular and lingual surfaces of all teeth, after staining with basic fuchsine, using numerical markers from 0 to 5 , which vary in accordance with the degree of pigmentation by the dye. The quantity of plaque is obtained by summing the scores and dividing them by the number of surfaces examined.

Subsequently, each volunteer received a brush and toothpaste, in accordance with their group (A or B). All of the participants were instructed to maintain their normal oral hygiene habits and to only use the toothpaste they had received for a period of 30 days. After this period 
had elapsed, they would return to the clinic so that the experiment could proceed to the next stage.

Stage 2: Thirty days later, the volunteers returned to the clinic, bringing their empty tubes of toothpaste. The same procedures as in stage 1 were carried out in order to obtain new $\mathrm{GBI}$ and $\mathrm{PI}$ values.

The examiner used in this experiment had been previously calibrated and the intraexaminer agreement was assessed through the intraclass correlation coefficient (ICC), which is it e equivalent of the Kappa coefficient for continuous variables. The agreement value was 0.878 for the plaque index, with a $p$-value of $p<0.001$. Concerning gingival bleeding, the same examiner was trained to perform the delicate probing (approximately $25 \mathrm{~g}$ of weight).

The clinical trial was recorded in REBEC (Registro Brasileiro de Ensaios Clínicoswww.rebec.com.br) under protocol number RBR-9F3CTB.

\section{Data Analysis}

The statistical analysis was performed using version 17.0 of SPSS software. For this clinical trial, the effects of two toothpastes on gingival bleeding and bacterial plaque were calculated based on the difference between the two examination stages (Baseline and 30 days). The following values were also calculated: the Excess Relative Risk (ERR); the Relative Risk Reduction (RRR); the Absolute Risk Reduction (ARR); and the Number Needed

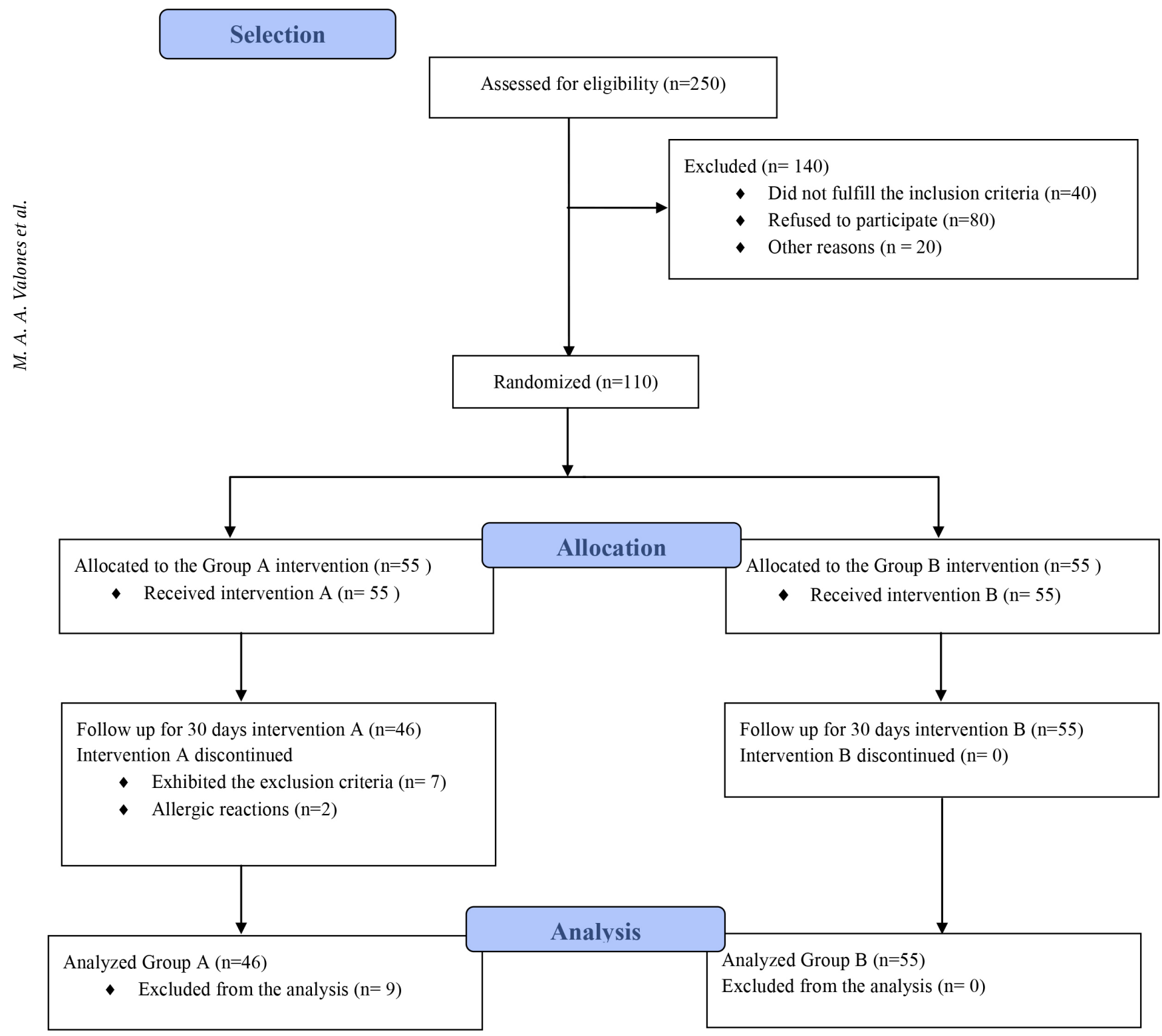

Figure 1. Flowchart of the participants. 
for Treatment (NNT).

\section{Results}

The level of participation of the sample was $91.81 \%$, since there were nine losses in Group A. The final sample of 101 patients had a mean age of $30.48 \pm 5.90$ years, with a minimum age of 18 years and a maximum age of 45 years. Of these, $38(37.6 \%)$ were male and 63 (62.4\%) were female (Table 1). Of the final sample, 46 belonged to Group $A$ and used toothpaste A (experimental), whereas 55 belonged to Group B (control).

The effects of the two toothpastes on gingival bleeding and bacterial plaque in the two stages of the study (Baseline and 30 days) are displayed in Table 2. The mean GBI and PI values decreased after 30 days, although the reduction was not statistically significant $(p>0.05)$ in the non-parametric Wilcoxon test, which was used to compare paired means.

Table 3 also displays the evolution of the patients in terms of gingival bleeding and the presence of plaque, in relation to the use of toothpastes $\mathrm{A}$ and $\mathrm{B}$.

Analysis of Table 2 and the calculation of the ratios or differences between groups $A$ and $B$ demonstrated that the use of toothpaste $A$ reduced the risk of gingival bleeding by $38 \%$ ( $E R R=0.38)$. In absolute terms, the reduction of this risk was $18 \%(A R R=0.18)$. In addition, the use of toothpaste A prevented one case of bleeding for every five patients

Table 1. Comparison of age and gender in relation to the use of toothpaste

\begin{tabular}{lcccc}
\hline \multirow{2}{*}{ Variable } & \multicolumn{2}{c}{ Toothpaste } & Total & p value \\
\cline { 2 - 3 } & $\mathrm{A}$ & $\mathrm{B}$ & & \\
\hline Male & $15(32.6 \%)$ & $23(41.8 \%)$ & $38(37.6 \%)$ & \\
Female & $31(67.4 \%)$ & $32(58.2 \%)$ & $63(62.4 \%)$ & $0.341^{1}$ \\
Age & $29.4 \pm 5.4$ & $31.4 \pm 6.2$ & $30.5 \pm 5.9$ & \\
Total & $46(100 \%)$ & $55(100 \%)$ & $101(100 \%)$ & $0.089^{2}$ \\
\hline
\end{tabular}

${ }^{1}$ Pearson's chi-squared test. ${ }^{2}$ Students t-test.

Table 2. Mean \pm standard deviation of the gingival bleeding index (GBI) and bacterial plaque index (PI) for the two time periods in the examinations (Baseline and 30 days), according to the use of toothpastes $\mathrm{A}$ and $\mathrm{B}$

\begin{tabular}{lcccc}
\hline Variable & Toothpaste & Baseline & 30 days & p value $^{1}$ \\
\hline \multirow{2}{*}{ GBI } & $\mathrm{A}$ & $10.47 \pm 15.92$ & $9.86 \pm 13.72$ & 0.555 \\
& $\mathrm{~B}$ & $11.76 \pm 18.32$ & $10.65 \pm 14.93$ & 0.112 \\
$\mathrm{PI}$ & $\mathrm{A}$ & $18.19 \pm 13.27$ & $17.04 \pm 11.18$ & 0.706 \\
& $\mathrm{~B}$ & $18.92 \pm 14.01$ & $16.21 \pm 12.72$ & 0.051 \\
\hline
\end{tabular}

${ }^{1}$ Wilcoxon test. treated (NNT=5). Similarly, the data showed that the use of toothpaste $B$ reduced the risk of gingival bleeding by $29.3 \%$ $(E R R=0.293)$. In absolute terms, the reduction of this risk was also $18 \%(A R R=0.18)$. Toothpaste $B$ also prevented one case of bleeding for every five patients treated (NNT=5). Concerning the plaque index, the efficiency of toothpaste A was measured at $22.7 \%(R R R=0.227)$. In absolute terms, the risk of an increase in the quantity of plaque was 14\% (ARR=0.14). The use of toothpaste A prevented one increase in plaque for every seven patients treated (NNT=7). Similarly, the effectiveness of treatment with toothpaste B was $28 \%(R R R=0.28)$. In absolute terms, the risk of an increase in the quantity of plaque was $14 \%(A R R=0.14)$. Thus, toothpaste $B$ prevented one increase in plaque for every seven patients treated (NNT=7).

\section{Discussion}

Natural products are a valuable and unexplored source of potentially effective antimicrobials, with low levels of toxicity. Recent advances in analytical technology, particularly those related to phytotherapy, have created a new era of anti-plaque therapies and natural products $(17,18)$. In this sense, plant extracts and their compounds appear as na alternative for the treatment of periodontal diseases in view of the fact that pharmacological research evoked the antibacterial and anti-inflammatory activities of rosemary. Such studies suggest that rosemary extract may act in the synthesis of anti-inflammatory leukotrienes in intact polymorphonuclear cells. In addition, it can inhibit 5-lipoxygenase, cyclooxygenase-2 (CPX-2) and the mobilization of intracellular calcium ions in mice with inflamed skin (19).

Faced with this, the aim of this randomized, controlled, open, double-blind, clinical trial was to investigate the clinical action of a new cosmeceutical (cosmetic with

Table 3. Evolution of the patients in terms of the gingival bleeding index and the bacterial plaque index in relation to the use of toothpastes $\mathrm{A}$ and $\mathrm{B}$

\begin{tabular}{lcccc}
\hline \multirow{2}{*}{ Variable } & \multicolumn{2}{c}{ Toothpaste } & Total & p value ${ }^{1}$ \\
\cline { 2 - 3 } & A & B & & \\
\hline GBI & & & & \\
Yes & $30(65.2 \%)$ & $26(47.2 \%)$ & $56(55.5 \%)$ & 0.071 \\
No & $16(34.8 \%)$ & $29(52.8 \%)$ & $45(44.5 \%)$ & \\
PI & & & & \\
Yes & $22(47.8 \%)$ & $34(61.8 \%)$ & $56(55.5 \%)$ & 0.159 \\
No & $24(52.2 \%)$ & $21(38.2 \%)$ & $45(44.5 \%)$ & \\
Total & $46(100 \%)$ & $55(100 \%)$ & $101(100 \%)$ & \\
\hline
\end{tabular}

${ }^{1}$ Pearson's chi-squared test. 
a therapeutic action) toothpaste containing extract of Rosmarinus officinalis Linn. (rosemary), which is widely used in food, cosmetics, spices and flavoring in many countries. A number of authors have conducted clinical trials to assess the effectiveness of toothpastes containing herbs, as well as, there are reports in the scientific literature of researches with mouthwashes which contained the rosemary in its composition $(5,18-20)$. However, the present study is the first to perform clinical analysis on rosemary using oral health indices and a defined therapeutic dose of the plant extract. Based on our results and those reported in the abovementioned studies, there is a consensus on the excellence of these herbal products, which exhibit an effective and satisfactory clinical performance. Rosemary is composed of terpenoids, flavonoids, phenols and essential oils. Each of these components has its own pharmacological properties (12), making it a valuable raw material for therapeutic products, such as the toothpaste produced for the present study. The satisfactory performance of this experimental toothpaste, in relation to gingival bleeding and plaque reduction, was due to the previously proven anti-inflammatory and antimicrobial therapeutic $\dot{s}$ properties of rosemary $(11,12,14)$ The experimental toothpaste was capable of reducing biofilm and decreasing gingival bleeding. The reduction of biofilm has also been demonstrated in vivo by Rasooli et al. (8), who used the essential oil of rosemary and suggested its use in new anti-caries treatment protocols.

Silva et al. (7) also confirmed the antimicrobial power of rosemary against oral bacteria in their research. These authors used common bacteria from the oral cavity (Streptococcus mitis, Streptococcus sanguis, Streptococcus sobrinus, Streptococcus mutans and Lactobacillus casei) in planktonic form. These findings were corroborated by Freires et al. (1) who conducted a systematic review on the antimicrobial power of the essential oils of medicinal plants, including rosemary.

The number needed to treat (NNT), which measures the impact of an intervention, has gained importance in recent years, as it represents the number of patients needed to be treated in order to prevent an undesirable effect (21). The results of the present randomized, clinical trial were positive for gingival bleeding, given that the reduction in bleeding was greater in the group that received the intervention. According to the findings of another study (6) natural products can provide an effective alternative to synthetic preparations, based on a promising and strategic approach to preventing and treating diseases and oral infections.

Although rosemary is a herbal product, two patients suffered allergic reactions to the intervention, which was immediately interrupted. The patients developed edema on the upper and lower lips, accompanied by plasmacytic gingivostomatitis. There are reports in the literature of allergic reactions to rosemary (22). Miroddi et al. (23) recently published a systematic review reporting several reactions to Rosmarinus officinalis, suggesting that Carnosol was the cause of these reactions.

Modern odontology is experiencing a period of evidence-based clinical approaches. Any product with a clinical application should pass through a series of tests in order to demonstrate its biocompatibility to the tissues in the oral cavity, as well as its effectiveness in these applications. Thus, in vivo studies are required to recommend ideal clinical protocols $(3,6)$ The present study shares this line of thinking, based on the execution of clinical trials (after pre-clinical trials) with a medicinal plant and the results obtained, which were comparable with products already available on the market.

According to Ledder et al. (24) plant extracts incorporated into toothpaste formulae add to the action of other components, improving the product. Therefore, a toothpaste such as the one produced in the present study, which contained fluoride and the extract of a medicinal plant with therapeutic properties (rosemary), is scientifically relevant and can be classified as a significant technological innovation.

The experimental toothpaste containing Rosmarinus officinalis was effective in controlling gingival bleeding and bacterial plaque in the sample in which it was used, when compared with conventional, fluoridated toothpaste. Therefore, it is a viable alternative to the synthetic products used in the field of odontology.

\section{Resumo}

0 presente estudo investigou a ação de uma pasta de dente feita a partir do extrato de Rosmarinus officinalis Linn. (Alecrim) em um ensaio clínico randomizado, controlado, aberto e duplo-cego. Cento e dez voluntários preencheram os critérios de inclusão e foram separados aleatoriamente em dois grupos de acordo com as pastas usadas: Grupo A (experimental) e Grupo B (controle). Eles foram avaliados no início e 30 dias após o estudo usando o indice de sangramento gengival (GBI) e o indice de placa (PI). A análise dos dados foi realizada para calcular os efeitos das duas pastas dentárias sobre sangramento gengival e placa, usando medidas como o excesso de risco relativo (ERR), a Redução do Risco Relativo (RRR), a Redução do Risco Absoluto (ARR) e o Número Necessário para Tratamento (NNT). As duas pastas de dentes proporcionaram resultados semelhantes em termos de redução do risco de sangramento gengival (relativo e absoluto): redução de $38 \%$ no Grupo $A, E R R=0,38$; Uma redução de 29,3\% no Grupo $B, E R R=0,293$; $A$ e $B$ reduziram-se em 18\% $A R R=0,18)$. As reduções na placa bacteriana também foram semelhantes (redução de 22,7\% no Grupo $A, R R R=0,227$, redução de $28 \%$ no Grupo $\mathrm{B}, \mathrm{RRR}=0,28)$. 0 número necessário para tratamento de sangramento $\mathrm{e}$ placa foi $A$ e $B N N T=5$ e $A$ e $B N N T=7$, respectivamente. A pasta de dente à base de alecrim tratou efetivamente o sangramento gengival e reduziu a placa bacteriana, quando comparada à pasta dentífrica convencional.

\section{References}

1. Freires IA, Denny C, Benso B, Alencar SM, Rosalen PL. Antibacterial activity of essential oils and their isolated constituents against 
cariogenic bacteria: a systematic review. Molecules 2015;20:73297358.

2. Chinsembu KC. Plants and other natural products used in the management of oral infections and improvement or oral health. Acta Trop 2016;154:6-18.

3. Sanz M, Serrano J, Iniesta M, Santa Cruz I, Herrera D. Antiplaque and antigingivits toothpastes. Monogr Oral Sci 2013;23:27-44.

4. Jain I, Jain P, Bisht D, Sharma A, Srivastava B, Gupta N. Use of traditional Indian plants in inhibition of caries-causing bacteriaStreptococcus mutans. Braz Dent J 2015;26:110-115.

5. Hebbal M, Ankola AV, Sharma R, Johri S. Effectiveness of herbal and fluoridated toothpaste on plaque and gingival scores among residents of a working women's hostel-a randomized Controlled Trial. Oral Health Prev Dent 2012;10:389-395.

6. Hotwani K, Baliga S, Sharma K. Phytodentistry: use of medicinal plants. J Complement Integr Med 2014;11:233-251.

7. Silva MSA, Silva MAR, Higino JS, Pereira MSV, Carvalho A de AT. Antimicrobial and nonstick activity of the extract of Rosmarinus officinalis Linn. On planktonic oral bacteria. Rev Bras Farmacogn 2008;18:236-240.

8. Rasooli I, Shayegh S, Taghizadeh M, Astaneh SD. Phitotherapeutic prevention of dental biofilm formation. Phytother Res 2008;22:11621167.

9. Radvar M, Moeintaghavi A, Tafaghodi M, Ghanbaria H, Fatemic $\mathrm{K}$, Mokhtaric MR, et al. Clinical efficacy of an herbal mouth wash composed of Salix alba, Malva sylvestrais and Althaea officinalis in chronic periodontitis patients. J Herb Med 2016;6:24-27.

10. Palombo EA. Traditional medicinal plant extracts and natural products with activity against oral bacteria: potential application in the prevention and treatment of oral diseases. Evid Based Complement Alternat Med 2011;680354:1-15.

11. Kazemi M, Rostami $H$, Ameri A. The study of compositions and antimicrobial properties of essential oil of Origanum vulgare and Rosmarinus officinalis on human pathogens. Curr Res Bacteriol 2012;5:1-12.

12. Begum A, Sandhya S, Ali SS, Vinod KR, Reddy S, Banji D. An in-depth review on the medicinal flora Rosmarinus officinalis (Lamiaceae). Acta Sci Pol Technol Aliment 2013;12:61-73.

13. Satyal P, Jones TH, Lopez EM, McFeeters RL, Ali NA, Mansi I, et al. Chemotypic Characterization and biological activity of Rosmarinus officinalis. Foods 2017:6:3.

14. Justo OR, Simioni PU, Gabriel DL, Tamashiro WM, Rosa P de T, Moraes AM. Evaluation of in vitro anti-inflammatory effects of crude ginger and rosemary extracts obtained through supercritical $\mathrm{CO}_{2}$ extraction on macrophage and tumor cell line: the influence of vehicle type. BMC Complement Altern Med 2015;15:390.

15. Sena KXFR, Andrade MSAS, Lima RC, Santos ER. Biological activities of Rosmarinus officinalis L. Bol Soc Brot Ser 1993;2:97-109.

16. Ainamo J, Bay I. Problems and proposals for recording gingivitis and plaque. Int Dent J 1975;25:229-235.

17. Turesky S, Gilmore ND, Glickman I. Reduced plaque formation by the chloromethyl analogue of vitamin C. J Periodontol 1970;41:41-43.

18. Azad MF Schwiertz A; Jentsch FR. Adjunctive use of essential oils following scaling and root planing - a randomized clinical trial. BMC Complement Altern Med 2016;16:171.

19. Mahyari S, Mahyari B, Emami SA, Malaekeh-Nikouei B, Jahanbakhsh SP, Sahebkar A, et al. Evaluation of the efficacy of a polyherbal mouthwash containing Zingiber officinale, Rosmarinus officinalis and Calendula officinalis extracts in patients with gingivitis: A randomized double-blind placebo-controlled trial. Complement Ther Clin Pract 2016;22:93-98.

20. Chen JX, Liu YY, Wang SX, Li XH. Efficacy of Crest Herbal Crystal Toohpaste in "Clearing Internal Heat": A randomized, double-blind clinical study. Evid Based Complement Alternat Med 2013; ID 807801.

21. Coutinho ESF, Cunha GM. Basic concepts of epidemiology and statistics for Reading controlled clinical trials. Rev Bras Psiquiatr 2005;27:146151.

22. Klarmann EG. Perfume dermatitis. Klarmann EG. Perfume dermatitis. Ann Allergy 1958;16:425-434.

23. Miroddi M, Calapai G, Isola $\mathrm{S}$, Minciullo PL, Gangemi S. Rosmarinus officinalis $\mathrm{L}$. as cause of contact dermatitis. Allergol Immunopathol 2014;42:616-619.

24. Ledder RG, Latimer J, Humpheys GJ, Sreenivasan PK, McBain AJ. Bacteriological effects of dentifrices with and without active ingredients of natural origin. Appl Environ Microbiol 2014;80:64906498.

Received June 11, 2018 Accepted August 2, 2018 